\title{
The effect of adaptation on taste jnds '
}

DONALD H. MCBURNEY, RICHARD A. KASSCHAU AND LLOYD M. BOGART

UNIVERSITY OF TENNESSEE

The jnd for $0.1 \mathrm{M} \mathrm{NaCl}$ was measured under two different adapting conditions. Following adaptation to $\mathrm{HOH}$ the jnd was $0.009 \mathrm{M}$ and after $0.1 \mathrm{M}$ adaptation it was $.018 \mathrm{M}$. The implications of this change in sensitivity with differing adaptation for Beidler's the ory are discussed.

In his quantitative theory of taste Beidler (1954, 1962) assumes that the sapid substance is absorbed onto receptive sites on the taste cell surface. The response measure that Beidler assumes to correspond in a one-to-one fashion with the number of filled sites is the steady-state, integrated activity of the chorda tympani (first-order) nerve. In other words, the hypothetical receptor sites are the functional units of the theory, and the proportion of sites filled is assumed to be reflected directly in the firing rate of the first-order nerve (Beidler, 1954). Beidler has also used the theory to predict the size of the human just noticeable difference ( $j n d$ ), and, from the cumulated jnds, to construct a magnitude scale that fits the theory (Beidler, 1958).

In several other sense departments, the size of the jnd varies with the state of adaptation. For vision the jnd is smallest when the adaptation level is equal to the standard (Keidel, Keidel, \& Wigand, 1961), and for hearing and warmth the jnd is smaller with higher adaptation, and vice versa for cold (Hedgecock, 1955; Kenshalo, Nafe, \& Brooks, 1961). In those senses, as well as in the sense of taste, the subjective magnitude function has a steeper slope with higher adaptation, and the maximum response may be unchanged (Hummel, 1926; McBurney, in press; Hedgecock, 1955; Stevens \& Stevens, 1963). It appears likely, therefore, that the jnd for taste may also be a function of adaptation. To test that hypothesis, we measured the jnd for the same concentration of salt standard under two adapting concentrations of salt.

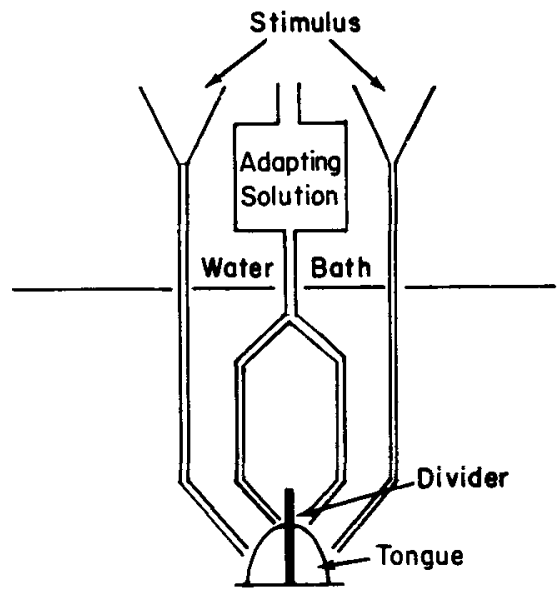

Table 1. Results of preliminary saudy

\begin{tabular}{lll} 
Subject & HOH Adaptation. & JND \\
\hline M. K. & $0.040 \mathrm{M}, \Delta \mathrm{V} / \mathrm{I}=.40$ & $0.1 \mathrm{M}$ Adaptation \\
L. B. & $0.043 \mathrm{M}, \Delta \mathrm{V} / \mathrm{I}=.43$ & $\Delta \mathrm{V} / \mathrm{I}=.10$ \\
\hline
\end{tabular}

\section{Apparatus and Procedure}

A plastic dam was arranged to divide the two halves of the extended tongue so that solutions on one side would not reach the other (Fig. 1). Both sides of the tongue were first adapted to the same solution and then-the two test stimuli were presented successively, with side and order randomized. The procedure prevented the first stimulus from changing the state of adaptation of the tongue for the next stimulus. All solutions were made from reagent grade $\mathrm{NaCl}$ in distilled water. The two adapting solutions were $\mathrm{HOH}$ and $0.1 \mathrm{M} \mathrm{NaCl}$. The standard was always $0.1 \mathrm{M} \mathrm{NaCl}$. The adapting solution flowed over the tongue for at least 20 sec. between trials.

\section{Preliminary Study}

The ascending method of limits was used in a preliminary study with a criterion of three correct in a row. Although the threshold for the two Ss is approximately one fourth as large under the $0.1 \mathrm{M}$ adaptation (Table 1), an unbiased estimate of the jnd is not possible using the method of limits.

\section{Method}

The method of constant stimuli was employed in the main study. Eight comparison stimuli were employed in each condition for subject DM and 10 for DS and BC. Under $\mathrm{HOH}$ the step size was $0.006 \mathrm{M}$, and under $0.1 M$ adaptation the step size was $0.002 \mathrm{M}$. All

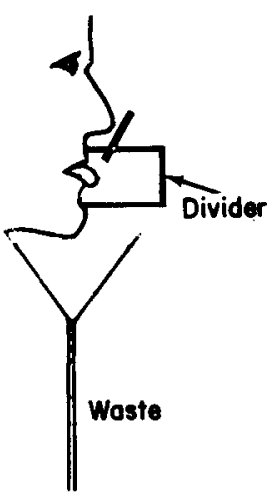

Fig. 1. Schematic diagram of the stimulator. 


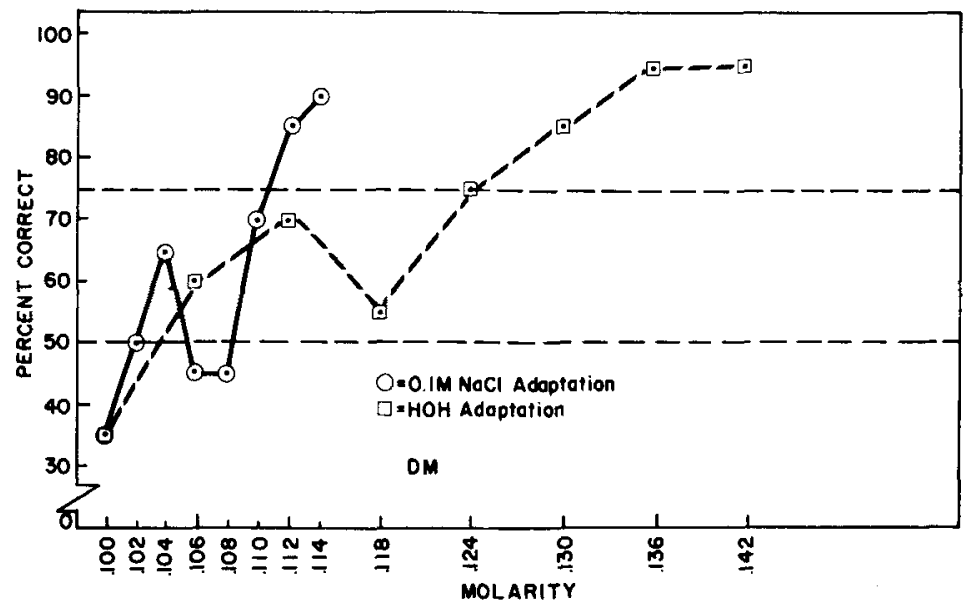

Fig. 2. Per cent correct responses as a function of stimulus concentration and adaptation condition, Subject DM. solutions were kept in a water bath at $34^{\circ} \mathrm{C}$. The order of adapting condition was ABBAABBA and each comparison stimulus was presented 20 times under each condition. The three Ss were the first author and two volunteers who were not informed of the purpose of the study.

\section{Resulfs}

The results are shown in Figs. 2-5. The jnd for DM was $0.011 \mathrm{M}$ under $0.1 \mathrm{M}$ adaptation and $0.024 \mathrm{M}$ under $\mathrm{HOH}$ adaptation. For DS the jnd was $0.009 \mathrm{M}$ and $0.018 \mathrm{M}$ for $0.1 \mathrm{M}$ and $\mathrm{HOH}$, respectively. Both curves for BC crossed the 75\% line at approximately $0.105 \mathrm{M}$, although it can be seen from Fig. 4 that the curves separate further as the strength of solution increases and that the $0.1 \mathrm{M}$ adapted curve reaches $100 \%$ at $0.110 \mathrm{M}$, while the $\mathrm{HOH}$ adapted curve does not reach $100 \%$ until $0.148 \mathrm{M}$.

\section{Discussion}

The data show good agreement among the three Ss, although the difference between the results for the two adapting conditions is not as great as in the preliminary study. However, the criterion of three correct in a row that was employed in the preliminary study is very strict. If the data of that study are reanalyzed as if each series had been ended with two correct responses in a row, we obtain the jnds shown in Table 2. These figures agree very well with the data obtained by the method of constant stimuli. A higher criterion exaggerates the difference between the conditions for reasons that are clear from comparison of the slopes of the response functions under the two adapting conditions in Figs. 2-5.

The average jnd for the three $\mathrm{Ss}$ is $0.009 \mathrm{M}$ for $0.1 \mathrm{M}$ adaptation and $0.018 \mathrm{M}$ for $\mathrm{HOH}$ adaptation. $\Delta \mathrm{I} / \mathrm{I}$ is 0.09 and 0.18 , respectively. These values fall in the range found by previous workers cited by Pfaffmann (1959), who reports a median $\Delta I / I$ of 0.15 . The data that this median represents are either average or minimum $\Delta \mathrm{I} / \mathrm{I}$ and are not directly comparable to our data. Interpolating the data of Holway and Hurvich (1937) yields a ratio of about 1.0 for $0.1 \mathrm{M}$ $\mathrm{NaCl}$. Schutz and Pilgrim (1957) found a ratio of 0.19 for $0.15 \mathrm{M}$, their weakest standard.

It will be noted that we employed the same $0.1 \mathrm{M}$

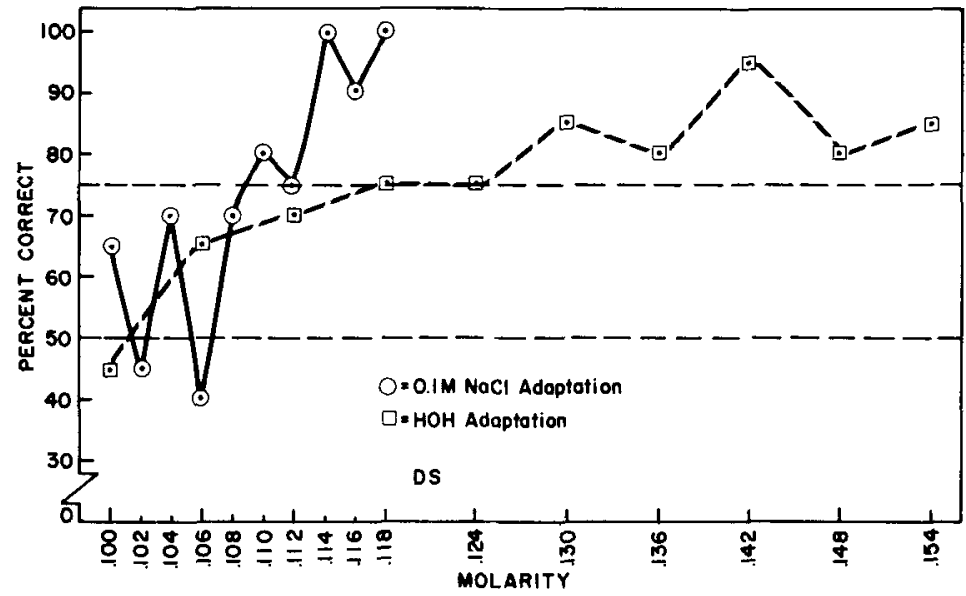

Fig. 3. Same as Fig. 2, Subject DS. 


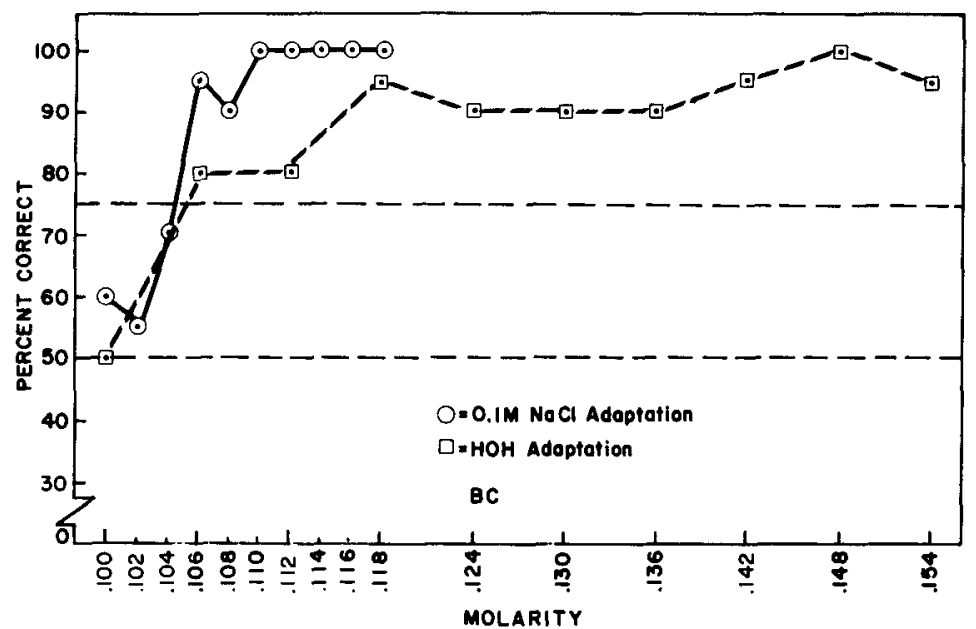

Fig. 4. Same as Fig. 2, Subject BC.

solution for one adapting solution and also as the standard. Since the taste of $\mathrm{NaCl}$ in this concentration is known to adapt completely, under $0.1 \mathrm{M}$ adaptation the $\mathbf{S}$ must choose between a solution that is tasteless and one that is salty, whereas, when the adaptation is to $\mathrm{HOH}$, the choice is between two salty solutions. Although it might be argued that a smaller jnd would be expected under salt adaptation, such a criticism amounts to restating our results in subjective terms.

These data present a difficulty for Beidler's theory inasmuch as adaptation may be expected, according to the theory, to fill a particular number of receptor sites. We have known that, in addition, the responsivity of the system, as it is measured by the jnd, is altered by adaptation. For other criticisms of Beidler's theory, see Oakley and Benjamin (1966, pp. 204-205).

With the extension of Bcidler's theory to the human jnd, we have three different equations predicting taste magnitude. Beidler's theory predicts that $\mathrm{C} / \mathbf{R}$ plotted against $\mathrm{C}$ will give a straight line. The prediction from Fechner's theory is that $R$ will be a straight-line function of $\log \mathrm{C}$. Stevens' methods yield a straight-line function when $\log R$ is plotted against $\log \mathrm{C}$. Beidler's formula is in the form of a hyperbola and Fechner's is logarithmic. These two types of equations are similar and often fit the same set of data equally well. The power function typically obtained by Stevens and others using his direct methods is quite different from the other two, however. Stevens' scale appears to be the most appropriate, primarily because it does not make the assumption of the psychological equivalence of the jnd. Furthermore, the results obtained by matching numbers to stimuli have been validated by the method of cross-modal matching. The assumption made by both Beidler and Fechner that each jnd represents the same increment in subjective intensity has been consistently found not to be true.

This experiment adds taste to the list of senses in which the jnd has been demonstrated to be a function of adaptation. Psychophysical scaling methods built upon the jnd cannot at the present time account for such changes.

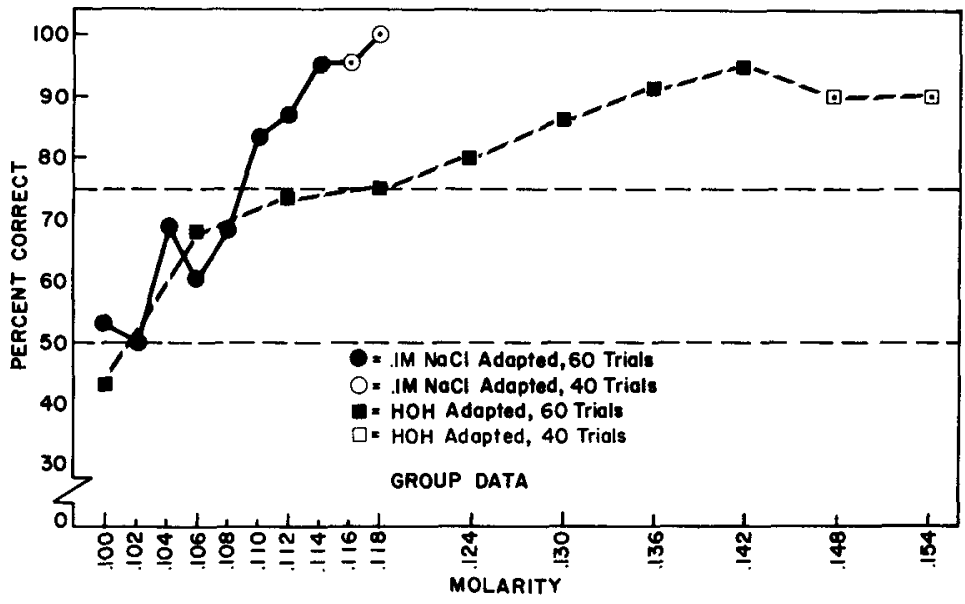

Fig. 5. Same as Fig. 2, group data. The filled symbols represent data for three Ss and the empty symbols are for two Ss. 
Table 2. Results of preliminary study reanalyzed as if each series had been terminated with two correct responses in a row

\begin{tabular}{lcc} 
Subject & HOH Adaptation & $0.1 \mathrm{M}$ Adaptation \\
\hline M. K. & $0.022 \mathrm{M}, \Delta \mathrm{V} / \mathrm{l}=.22$ & $0.008 \mathrm{M}, \Delta \mathrm{V} / \mathrm{I}=.08$ \\
L. B. & $0.018 \mathrm{M}, \Delta \mathrm{V} / \mathrm{I}=.18$ & $0.207 \mathrm{M}, \Delta \mathrm{V} / \mathrm{I}=.07$ \\
\hline
\end{tabular}

\section{References}

Beidler, L. M. An electrophysiological study of the response of the chemoreceptors of the tongue of the rat to salt stimulation. $J$. Neurophysiol., 1953, 16, 595-609.

Beidler, L. M. A theory of taste stimulation. J. gen. Physiol., 1954, 38, 133-139.

Beidler, L. M. The physiological basis of taste psychophysics. In Second Symposium on Physiological Psychology, ONR Symposium Report ACR-30, 1958.

Beidler, L. M. Taste receptor stimulation. In J. A. V. Butler, H. E. Huxley \& R. E. Zirkel (Eds.), Progress in biophysics and biophysical chemistry. New York: Pergamon Press, 1962, XII, 107151.

Hedgecock, L, D. The measurement of auditory recruitment. $A, M$. A. Arch. Otolaryng., 1955, 62, 515-527.
Holway, A. H., \& Hurvich, L. M. Differential sensitivity to salt. Amer. J. Psychol., 1937, 49, 37-48.

Hummel, E. Die veranderung des systemes der temperaturempfindungen durch die adaptation. Arch. Ges. Psychol., 1926, 57, 305-394.

Keidel, W. D., Keidel, U. O., \& Wigand, M. E. Adaptation: Loss or gain of sensory information? In W. A. Rosenblith (Ed.), Sensory communication. New York: Wiley, 1961, 319-338.

Kenshalo, D. R., Nafe, J. P., \& Brooks, B. Variations in thermal sensitivity. Science, 1961, 134, 104-105.

McBumey, D. H. Magnitude estimation of the taste of sodium chloride after adaptation to sodium chloride. J. exp. Psychol., 1966. 72, 869-873.

Oakley, B., \& Benjamin, R. M. Neural mechanisms of taste. Physiol. Rev., 1966, 46, 173-211.

Pfaftmann, C. The sense of taste. In J. Field (Ed.), Handbook of physiology, I. Washington, D. C.: American Physiological Society, 1959, 507-533.

Schutz, H. G., \& Pilgrim, F. J. Differential sensitivity in gustation. J. exp. Psychol., 1957, 54, 41-48.

Stevens, J. C., \& Stevens, S. S. Brightness function: Effects of adaptation. J. Opt. Soc. Amer., 1963, 55, 375-385.

Note

1. These results were presented at the 1966 meeting of the Psychonomic Society. We thank Carl Pfaffmann. Trygg Engen, and William Cain for helpful discussions.

(Accepted for publication February 20, 1967.) 